\title{
Algılanan Bağlılık Tabanlı İnsan Kaynakları Sisteminin Algılanan Gelişim Kültürü ve Yenilikçi İş Davranışına Etkisi
}

\author{
Canan Ceylan \\ Uludağ Üniversitesi
}

Ocak/January 2013, Cilt/Vol: 15, Sayı/Num: 1, Page: $42-58$

ISSN: 1303-2860, DOI: 10.4026/1303-2860.2013.0218.x

Makalenin on-line kopyasına erişmek için:
http://www.isguc.org/?p=article\&id=501\&cilt=15\&sayi=1\&yil=2013
To reach the on-line copy of article:
http://www.isguc.org/?p=article\&id=501\&cilt=15\&sayi=1\&yil=2013
Makale İçin İletişim/Correspondence to: ccanan@uludag.edu.tr




\title{
(c) $2000-2013$ \\ “İş,Güç” Endüstri İlişkileri ve İnsan Kaynakları Dergisi \\ "İş, Güç" The Journal of Industrial Relations and Human Resources
}

\author{
Ocak/January 2013, Cilt/Vol: 15, Sayı/Num: 1, Page: 42-58 \\ ISSN: 1303-2860, DOI: 10.4026/1303-2860.2013.0218.x
}

\begin{abstract}
“İş,Güç” Endüstri İlişkileri ve İnsan Kaynakları Dergisi, yılda dört kez yayınlanan hakemli, bilimsel elektronik dergidir. Çalışma hayatına ilişkin makalelere yer verilen derginin temel amacı; belirlenen alanda akademik gelişime ve paylaşıma katkıda bulunmaktadır.
\end{abstract}

“İş,Güç” Endüstri İlişkileri ve İnsan Kaynakları Dergisi'nde, 'Türkçe' ve 'Ingilizce' olarak iki dilde makale yayınlanmaktadır. Dergi ulusal ve uluslararası birçok indekste taranmaktadır. (CABELLS DIRECTORY, EBSCO SOCINDEX, INDEX ISLAMICUS, INDEX COPERNICUS, WORLDWIDE POLITICAL SCIENCE ABSTRACTS, SOCIOLOGICAL ABSTRACT, ULAKBIM SOSYAL BILIMLER VERITANI, ASOS INDEX)

\section{Editör / Editor in Chief}

Aşkın Keser (Uludağ University)

\section{Editör Yardımcıları / Co-Editors Şenol Baştürk (Uludağ University) K.Ahmet Sevimli (Uludağ University) Gözde Yılmaz (Marmara University)}

\section{Uygulama / Design}

Yusuf Budak (Kocaeli University)

\section{Tarandığı Indeksler}

ASOS INDEX

CABELLS DIRECTORY

EBSCO SOCINDEX

INDEX ISLAMICUS

INDEX COPERNICUS

SOCIOLOGICAL ABSTRACT

ULAKBIM SOSYAL BILIMLER

VERITANI

WORLDWIDE POLITICAL SCIENCE

ABSTRACTS

\author{
Yayın Kurulu / Editorial Board \\ Dr. Erdem Cam (CASGEM) \\ Yrd. Doç. Dr. Zerrin Fırat (Uludağ University) \\ Doç. Dr. Aşkın Keser (Uludağ University) \\ Prof. Dr. Ahmet Selamoğlu (Kocaeli University) \\ Yrd. Doç. Dr. Ahmet Sevimli (Uludağ University) \\ Doç. Dr. Abdulkadir Şenkal (Kocaeli University) \\ Doç. Dr. Gözde Yılmaz (Marmara University) \\ Yrd. Doç. Dr. Memet Zencirkıran (Uludağ University) \\ Ulus/ararası Danışma Kurulu / International Advisory Board \\ Prof. Dr. Ronald Burke (York University - CA) \\ Assoc. Prof. Dr. Glenn Dawes (James Cook University - AU) \\ Prof. Dr. Jan Dul (Erasmus University - NL) \\ Prof. Dr. Alev Efendioğlu (University of San Francisco - USA) \\ Prof. Dr. Adrian Furnham (University College London - UK) \\ Prof. Dr. Alan Geare (University of Otago - NZ) \\ Prof. Dr. Ricky Griffin (TAMU-Texas A\&M University - USA) \\ Assoc. Prof. Dr. Diana Lipinskiene (Kaunos University - LT) \\ Prof. Dr. George Manning (Northern Kentucky University - USA) \\ Prof. Dr. William L. Murray (University of San Francisco - USA) \\ Prof. Dr. Mustafa Özbilgin (Brunel University - UK) \\ Assoc. Prof. Dr. Owen Stanley (James Cook University - AU) \\ Prof. Dr. Işık Urla Zeytinoğlu (McMaster University - CA) \\ Ulusal Danışma Kurulu / National Advisory Board \\ Prof. Dr. Yusuf Alper (Uludağ University) \\ Prof. Dr. Veysel Bozkurt (İstanbul University) \\ Prof. Dr. Toker Dereli (Işık University) \\ Prof. Dr. Nihat Erdoğmuş (Şehir University) \\ Doç. Dr. Mustafa Kurt (Yalova University) \\ Prof. Dr. Ahmet Makal (Ankara University) \\ Prof. Dr. Süleyman Özdemir (İstanbul University) \\ Prof. Dr. Ahmet Selamoğlu (Kocaeli University) \\ Prof. Dr. Nadir Suğur (Anadolu University) \\ Prof. Dr. Nursel Telman (Maltepe University) \\ Prof. Dr. Cavide Uyargil (Istanbul University) \\ Prof. Dr. Engin Yıldırım (Constitutional Court of Turkey) \\ Doç. Dr. Arzu Wasti (Sabancı University)
}

Dergide yayınlanan yazılardaki görüşler ve bu konudaki sorumluluk yazarlarına aittir. Yayınlanan eserlerde yer alan tüm içerik kaynak gösterilmeden kullanılamaz.

All the opinions written in articles are under responsibilities of the authors. The published contents in the articles cannot be used without being cited. 


\title{
Algılanan Bağlılık Tabanlı İnsan Kaynakları Sisteminin Algılanan Gelişim Kültürü ve Yenilikçi İş Davranışına Etkisi
}

\author{
Canan Ceylan
}

Uludağ Üniversitesi

\begin{abstract}
The purpose of this study is to examine the effect of perceived commitment-based human resource system on perceived developmental culture and innovative work behavior. Data of the study was gathered from 121 employees in companies that produce spare parts for the automotive industry. Data collection was carried out via a questionnaire survey. According to the findings of the study, perceived commitment-based human resource system has positive effect on perceived developmental culture. Additionally developmental culture partially mediates the relationship between perceived commitment-based human resource system and innovative work behavior.
\end{abstract}

Keywords: Commitment-Based Human Resource System, Developmental Culture, Innovative Work Behavior, Human Capital, Management

\section{Özet}

Bu araştırmanın amact, algllanan bağgllık tabanlı insan kaynakları sisteminin algılanan gelişim kültürüne ve yenilikçi iş davranışına etkisini incelemektir. Araştırma verileri taşıt araçları imalat endüstrisine parça üreten işletmelerde görev yapan 121 çalı̧̧andan toplanmıştır. Veri toplama çalışması anket yöntemiyle gerçekleştirilmişstir. Araştırma sonucunda elde edilen bulgulara göre, algılanan bağlllık tabanlı insan kaynakları sisteminin algllanan gelişim kültürü̈nü pozitif yönde etkilediği belirlenmiştir. Ayrıca, algılanan bağlılık tabanlı insan kaynaklar sistemi ile yenilikçi iş davranışı arasındaki iliş̧kide gelişim kültürünün kssmi aracılık etkisi olduğu ortaya çıkmıştır.

Anahtar Kelimeler: Bağlllık Tabanlı İnsan Kaynakları Sistemi, Gelişim Kültürü, Yenilikçi İs Davranışı, İnsan Sermayesi, Yönetim 


\section{Giriş}

Günümüzün bilgiye dayalı iş çevresinde işletmelerin sürdürülebilir rekabet avantaj1 sağlaması için insan sermayesi önemli bir kaynaktır (Barney ve Wright, 1998). İnsan kaynakları uygulamaları, yüksek kaliteli bir insan sermayesi havuzu oluşturarak ve bireylerin örgüt amaçlarıyla uyumlu davranışlar sergilemelerini sağlayarak insan sermayesinin rekabette avantaj yaratmasında önemli bir rol oynar (Wright ve diğ., 1994).

İşletmeler, insan kaynakları uygulamaları aracılığıyla çalışanların bilgi, beceri, tutum, davranış ve motivasyonunu etkileyebilir (Wright ve diğ., 1994; Jackson ve diğ., 1989; Schuler ve Jackson, 1987). Bu bağlamda, birey-örgüt ilişkisinin, diğer bir deyişle, örgütün çalışanlarından beklediği katkılar ile bu katkılarda bulunmalarını sağlamak için onlara sunduğu özendirici araçlar (Tsui ve diğ., 1997) arasındaki dengenin hangi yönde kurulduğu önem taşımaktadır. İnsan kaynakları yönetimi yazınında, birey-örgüt ilişkisine dayalı olarak çeşitli insan kaynakları uygulamaları geliştirilmiştir. Bu uygulamalardan biri de; uzun vadeli, karşılıklı yatırım ve bağlılığa dayalı bir birey-örgüt ilişkisini vurgulayan bağlllık tabanlı insan kaynakları uygulamalarıdır (Tsui ve diğ., 1995; Arthur, 1994; Arthur, 1992). Bu uygulamalar, uzun vadeli bağlllık yaratan bir çalışma ortamının oluşmasını ve işletmeye özel bilgi, beceri ve yeteneklerin gelişmesini sağlar (Delery ve Doty, 1996). Bu çalışmada, stratejik insan kaynakları yönetimi yazınındaki öneriler doğrultusunda, bağlılık tabanlı insan kaynakları uygulamaları paketi, insan kaynakları sistemi olarak değerlendirilmiştir.

İnsan kaynakları yönetimi yazınında bağ lılı̆ğ artırma amaçlı yapılandırılmış insan kaynakları sistemi ile gelişim kültürü ilişkisini destekleyici bazı çalışmalar yer almaktadır (Wei ve diğ., 2011; Hartog ve Verburg, 2004; Lau ve Ngo, 2004). Ancak bu çalışmaların genellikle örgütsel düzeyde yapıldığı görülmektedir. $\mathrm{Bu}$ kapsamda, algılanan bağlılık tabanlı insan kaynakları sisteminin örgüt kültürünün gelişime yönelimli şekilde algılanmasında gösterdiği etkiyi inceleyen çalışan düzeyindeki görgül araştırmaların gerekli olduğu düşünülmektedir.
İnsan kaynakları yönetimi yazınında yapılan çalışmalar, algılanan bağlılık tabanlı insan kaynakları sisteminin çeşitli tutum ve davranışları pozitif yönde etkilediğini göstermektedir (Kwon ve diğ., 2010; Uen ve diğ., 2009; Nishii ve di diğ., 2008; Dorenbosch ve diğ., 2005; Lee ve Bruvold, 2003). Ancak, bu çalışmaların bağlılık tabanlı insan kaynakları sisteminin tutum ve davranışları doğrudan etkileyip etkilemediği ile ilgili farklı sonuçlar ürettiği görülmektedir. İlgili yazında yapılan inceleme sonucunda, algılanan bağlllık tabanlı insan kaynakları sistemi ve yenilikçi iş davranışı arasındaki ilişkinin doğrudan gerçekleşip gerçekleşmediği ve bu ilişkide hangi aracıların rol oynadığı konusunun tam anlamiyla bilinmediği düşünülmektedir. Ayrıca bu ilişkiyi bireysel düzeyde inceleyen çalışmaların az sayıda olduğu da dikkat çekmektedir. Bu çalışmaların genellikle örgütsel düzeyde gerçekleştirildiği ve bağlılık tabanlı insan kaynakları sistemiyle işletmenin yenilik performansı arasındaki nedensel ilişkilerin incelendiği görülmektedir (Ceylan, 2013; Lopez-Cabrales ve diğ., 2009; Collins ve Smith, 2006; Shipton ve diğ., 2005). Aynı zamanda, örgüt kültürünün aracıllk etkisini inceleyen çalışmaların genellikle örgütsel düzeyde yapıldığı (Wei ve diğ., 2011; Chan ve diğ., 2004; Hartog ve Verburg, 2004), algilanan bağlılık tabanlı insan kaynakları sisteminin algılanan örgüt kültürü aracılığıyla yenilikçi iş davranışına etkisinin yeterince incelenmediği düşünülmektedir. Örgütlerde çeşitli uygulamaların hayata geçirilmesinin yanı sıra, çalışanların bu uygulamaları hangi yönde algiladığı ve değerlendirdiği de oldukça fazla önem taşımaktadır. Çalışanların uygulamaları olumlu yönde değerlendirmesi; örgütü ve yönetimi destekleyici yönde algılamalarını, böylece arzu edilen tutum ve davranışları sergilemelerini sağlayarak örgütün stratejik amaçlara ulaşmasındaki katkılarını artırıcı bir etki yaratabilir.

$\mathrm{Bu}$ araştırmanın amacı, algılanan bağlılık tabanlı insan kaynakları sisteminin algılanan gelişim kültürüne ve yenilikçi iş davranışına etkisini incelemek ve bu amaca dayalı olarak geliştirilen hipotezleri test etmektir. 
Yukarıdaki değerlendirmelerin ışı̆̆ı altında, araştırma bulgularının insan kaynakları yönetimi yazınına bağlllık tabanlı insan kaynakları sistemlerinin çalışanların davranışları üzerindeki etkisi ve bu etkinin nedenlerini açılama yönünde katkı sağlaması beklenmektedir.

\section{Teori ve Hipotezler}

\subsection{Bağlılık Tabanlı İnsan Kaynakları Sistemi}

Stratejik insan kaynakları yönetimi yazınında araştırmacılar, işletme sorunlarını çözümlemede insan kaynakları sisteminin rolünü belirtmektedir (Becker ve Huselid, 2006). İnsan kaynakları sistemi, değer yaratan ve örgütün yeteneklerini artıran stratejik bir varlık olarak değerlendirilmiştir (Becker ve Gerhart, 1996). Bu kapsamda, insan sermayesinin kazandığı işletmeye özel beceriler rakipler tarafından kolayca taklit edilemez (Barney ve Wright, 1998). Bir sistem olarak insan kaynakları uygulamaları; birbirini tamamlayan, güçlendiren ve birbiriyle ilişkili insan kaynakları uygulamaları aracılığıyla bireylerin ve örgütün performansinı etkiler (Laursen ve Foss, 2003; Becker ve Huselid, 1998; Huselid, 1995; McDuffie, 1995). Laursen ve Foss (2003)'un belirttiği gibi, bir araya getirilmiş insan kaynakları uygulamalarının yenilik performansı üzerinde oluşturduğu etki, her bir insan kaynakları uygulamasının ayrı olarak oluşturduğu etkiden daha fazla olabilir. İçsel olarak tutarlı ve uyumlu bir insan kaynakları sistemi; entelektüel sermayenin edinimi, motivasyonu ve gelişimini destekler (Becker ve Huselid, 1998).

Lepak ve diğerlerine (2006) göre, insan kaynakları sistemlerinin çeşitli stratejik amaçlara ulaştırmak üzere yapılandırılması gereklidir. Bu kapsamda, bağlılık tabanlı insan kaynakları sistemleri, çalışanların bağlılığını artırmak amacıyla yapılandırılmış insan kaynakları uygulamalarını içermektedir

(Arthur, 1992). Bağlılık tabanlı insan kaynakları uygulamaları, insan kaynağının eşsiz ve değerli olduğu anlayışından hareketle, çalışanların beceri ve yeteneklerini geliştirmeyi amaçlamaktadır (Lepak ve Snell, 2002).

$\mathrm{Bu}$ çalışmada ele alınan bağlılık tabanlı insan kaynakları uygulamaları; çalışanların katılımını artırmak için yetkilendirme, katılımcı karar alma ve iş rotasyonu uygulamaları; insan kaynağına yapılan yatırımın korunması ve uzun vadeli bağllı̆̆g sağlamak amaciyla istihdam güvencesi verme, çalışanların öğrenme potansiyelini ve işletmeye özel yeterliklerini artırmayı amaçlayan işe alma ve seçme süreci, çalışanların işletmeye özel beceriler geliştirmelerini sağlayan eğitim ve geliştirme faaliyetleri, çalışanların gelişimini sağlayan ve sürekli ve yapıcı bir geri bildirim vermeye odaklı performans değerlemesi ve uzun vadeli bağlllık odaklı ücretlendirme ve ödüllendirme gibi uygulamaları içermektedir (Lepak ve Snell, 2002, 1999). Bu çalışmada bağlılık tabanlı insan kaynakları sistemi; yukarıda ayrıntılı olarak açıklandığı gibi, yüksek bağlılık yaratmak amacıyla geliştirilmiş iş tasarımı, işe alma ve seçme, eğitim ve geliştirme, performans değerleme ve ücretlendirme uygulamaları (Lepak ve Snell, 2002, 1999) paketi olarak ele alınmıştır.

Algılanan bağlılık tabanlı insan kaynakları sistemi, diğer bir deyişle, insan kaynakları sisteminin bağlllığ desteklemesine ilişkin çalışanların algıları, sergilenen tutum ve davranışlar üzerinde oldukça etkili olabilir. Arthur (1994: 672)'un belirttiği gibi, bağlllık tabanlı insan kaynakları sistemleri, örgüt ve bireylerin amaçları arasında psikolojik bir bağ kurarak, çalışanların arzu edilen tutum ve davranışlar sergilemelerini sağlar. Bu durum, çeşitli uygulamaların yarattığı etkiyle gelişen çalışma ortamında oluşabilir. Bağlılık tabanlı insan kaynakları uygulamalarının gerçekleştirilmesiyle çalışanların karar alma sürecine katılımlarının artması, yöneticilerle daha etkili iletişim kurabilme olanağına sahip olmaları ve daha fazla eğitim ve geliştirme fırsatları elde etmeleri mümkündür; bu destekleyici ortam, uygulamaların çalışanlar tarafından olumlu yönde algılanmasını ve yönetimin beklentilerinin daha iyi anlaşılmasını sağlayabilir (Chang, 2005). Bununla beraber, Uen ve diğerleri (2009), 
örgütte düşük düzeyde bağlllık tabanlı insan kaynakları sisteminin var olması halinde, örgütün çalışanlar tarafından eğitim, kariyer geliştirme, v.b. fırsatları sunmayı taahhüt etmediği yönünde algilanabileceğini vurgulamıştır.

\subsection{Yenilikçi İş Davranışı}

Yenilikçi iş davranışı (Janssen, 2000:288); rol performansına, gruba veya örgüte yararlı olması için; çalışma rolünde, grup içinde veya örgütte yeni fikirlerin istekli olarak üretilmesi, tanitılması ve uygulanmasıdır. Yapılan araştırmalarda yaratıcılık ve yenilikçiliğin fikir üretme ve fikir uygulama arasında değişen şekilde kullanılmasına rağmen (Martins ve Terblanche, 2003), bu çalışmada Scott ve Bruce (1994)'un yaklaşımıyla yenilikçilik, fikir üretme ve fikir uygulamanın her ikisini de içine alan bir süreç olarak değerlendirilmiştir.

Scott ve Bruce (1994:582)'a göre, yenilikçi iş davranışı, her adımda gerekli olan çeşitli davranışları kapsayan bir süreçtir, bireylerin bu davranışların herhangi bir bileşimini herhangi bir zamanda sergilemesi beklenebilir. Yenilikçi iş davranışı süreci; fikir üretme, fikir tanıtımı ve fikir uygulamasından oluşan üç farklı davranış grubu olarak değerlendirilmiştir (Janssen, 2000). Bu sürecin ilk adımında, fikir üretme, diğer bir deyişle, orijinal ve kullanışlı fikirlerin üretimi (Amabile ve diğ., 1996:1155) gerçekleşir. Bu adım; bilgi toplamak, problemi tanımlamak, yeni çalışma yöntemleri araştırmak ve probleme çözüm üretmek gibi davranışları içerir (Janssen, 2000). Fikir üretildikten sonra gerçekleşen fikir tanıtımı aşamasında, birey çevresindeki kişilerle sosyal ilişkiler kurarak fikrinin kabul edilmesini ve önemli kişilerin fikrine destek vermesini sağlamaya çalışır (Janssen, 2000; Scott ve Bruce, 1994). Sürecin son adımı ise, fikrin uygulanmasıdır. Bu adımda, birey bir model geliştirerek veya bir ilk örnek üreterek fikrini uygulamaya dönüştürür ve işe yararlığını değerlendirmeye çalışır (Janssen, 2000; Scott ve Bruce, 1994).

\subsection{Gelişim Kültürü}

Rekabet eden değerler modeline dayalı olarak örgütlerde kültür tipleri grup, gelişim, rasyonel ve hiyerarşik kültür olmak üzere dört farklı tipte ele alınmıştır (Quinn ve Spreitzer, 2001; Cameron ve Quinn, 1999; Quinn, 1988). $\mathrm{Bu}$ çalışmada diş odaklılık ve esnekliği vurgulayan gelişim yönelimli kültür tipi (Quinn ve Spreitzer, 2001; Cameron ve Quinn, 1999; Quinn, 1988) incelenmiştir. Gelişim kültürü; büyüme, gelişme, kaynak kazanımı, yaratıcılık ve dış çevreye uyumu vurgular; liderler girişimci, vizyoner ve risk alıcıdır (Denison ve Spreitzer, 1991). Yapılan bazı çalışmaların bulgularına göre, gelişim kültürü çalışanların girişimci davranışlarını ve örgüte olan güvenini olumlu yönde etkilemektedir (Akkoç ve diğ., 2012a; Akkoç ve diğ., 2012b).

Gelişim kültürü 'yenilik-merkezli kültür' (Palthe ve Kossek, 2003:298) olarak nitelendirilmiştir. Gelişim kültürü yenilikçilik odaklı yönetsel tutum ve davranışları destekleyicidir (Kayalar ve Özmutaf, 2007). İşletmede yenilikçiliği destekleyen bir kültür yaratıcılığa katkıda bulunmaktadır (Andriopoulos, 2001). Yenilikçiliği destekleyen bir kültürde bireyler girişimci, mücadeleci, yaratıcı, sonuç odaklı ve risk alıcı olabilir (Wallach, 1983).

\subsection{Bă̆glılı Tabanlı İnsan Kaynakları Sistemi, Gelişim Kültürü ve Yenilikçi İş Davranışı İlişkisi}

İnsan kaynakları uygulamalarının örgüt kültürü üzerinde etkisi mevcuttur (Hartog ve Verburg, 2004; Lau ve Ngo, 2004). Bu bağlamda, insan kaynakları uygulamaları örgüt kültürünün oluşumu ve yönetimi sürecinde önemli bir role sahiptir (Schneider, 1988; Wilkins, 1984; Tichy, 1982; Schwartz ve Davis, 1981). Jackson ve Schuler (1995)'in vurguladığı gibi, örgüt kültürü insan kaynakları yönetiminin ayrılmaz bir parçasıdır. Bağlılık artırma amacıyla yapılandırılmış insan kaynakları uygulamaları 'kültür yerleştiren mekanizmalar' (Hartog ve 
Verburg, 2004: 59) olarak nitelendirilmiştir. Bu bağlamda, insan kaynakları uygulamaları, çalışanları belirli tutum ve davranışları sergileme yönünde motive ederek örgütün kültürünü yapılandırmaktadır (Bowen ve Ostroff, 2004; Cabrera ve Bonache, 1999; Wilkins, 1984; Tichy, 1982). Bowen ve Ostroff (2004)'a göre, insan kaynakları sistemi çalışanların algılarını, tutumlarını ve davranışlarını şekillendirir, diğerleriyle paylaşmalarını sağlar. Böylece, insan kaynakları sistemi sergilenmesi gerekli davranışların çalışanlara iletilmesini ve çalışanların benzer tutum ve davranışlar göstermelerini sağlar (Bowen ve Ostroff, 2004). Bağlılık tabanlı insan kaynakları sistemleri yenilikçilik ve girişimciliğe önem verilen bir örgüt kültürü tipinin oluşmasını sağlayabilir (Hartog ve Verburg, 2004; Lau ve Ngo, 2004). Böylece çalışanlar işletmenin benimsediği kültürü örgüt ortamında deneyimleyebilir.

Yukarıdaki açılamaların ışığı altında, algılanan bağlılık tabanlı insan kaynakları sisteminin algilanan gelişim kültürünü etkileyebileceği önerilmektedir. Bu doğrultuda, aşağıdaki hipotez geliştirilmiştir:

Hipotez 1: Algılanan bağlılık tabanlı insan kaynakları sistemi ile algılanan gelişim kültürü arasında pozitif bir ilişki vardır.

Bağlılık tabanlı insan kaynakları sistemi yenilikçi iş davranışı üzerinde doğrudan etki göstermeyebilir, bu ilişkide çeşitli aracılar rol oynayabilir. İnsan kaynakları yönetimi yazınında, bu ilişkide etkili olabilecek aracıları inceleyen bazı çalışmalar bulunmaktadır. Örneğin, Dorenbosch ve diğerlerinin (2005) çalışma sonuçlarına göre, insan kaynakları sistemini bağlılığı desteklediği yönünde algılayan çalışanların işleri üzerinde daha fazla sahiplik duygusu hissettikleri, böylece daha fazla yenilikçi iş davranışı sergiledikleri tespit edilmiştir. Ramamoorthy ve diğerlerinin (2005) çalışmasında ise, algılanan ücretleme ve işte özerklik uygulamalarının psikolojik sözleşme aracılığıyla yenilikçi iş davranışını etkilediği ortaya çıkmıştır.

Algılanan bağlılık tabanlı insan kaynakları sistemi algılanan gelişim kültürü aracılığıyla yenilikçi iş davranışlarını etkileyebilir. Çalışanların örgütlerdeki uygulamalara yönelik algıları sergiledikleri yenilikçi iş davranışları üzerindeki etkisi açısından önemli bir yere sahiptir. Axtell (2000), yenilik yapmada başarılı olmak için destekleyici bir örgüt ortamının önemini vurguladığı çalışmada, örgütte gerçekleşen uygulamalara yönelik çalışanların algılarının yenilik sürecinin çeşitli aşamalarında ve yenilikçi davranışlar üzerinde etki gösterdiğini ortaya koymuştur. Bu bağlamda, algılanan insan kaynakları sistemi, çalışanların bağlılı̆̆ını sağlamada ve yenilikçi iş davranışlarını istekli bir şekilde sergilemelerinde etkilidir (Dorenbosch ve diğ., 2005). Bu ilişkiyi anlamak açısından bağlılığı artırmayı sağlayan bazı insan kaynakları uygulamalarının yenilikçi iş davranışına etkisi örnek olarak gösterilebilir. Bu kapsamda eğitim faaliyetleri; sorgulama, paylaşma ve gayret etme; performans değerleme ve ödüllendirme; öğrenme isteğine sahip olma, risk alma ve etkili iletişim kurma gibi yenilik yapma yönündeki davranışların gelişmesini sağlayabilir (West ve diğ., 2004). Gelişim odaklı geri bildirimler ise, çalışanların yenilikçi davranışlar göstermesinde özendiricidir (Egan, 2005). Fernandez ve Pitz (2011)'in yaptığ 1 araştırmaya göre; algılanan ödüllendirme, yetkilendirme, katılımcı karar alma ve eğitim ve geliştirme uygulamaları çalışanların yenilikçi davranışlarını olumlu yönde etkilemiştir.

Farklı örgüt tipleri, çalışanların tutum ve davranışları üzerinde farklı etkiler gösterebilir (Lau ve Ngo, 1996). Bu bağlamda gelişim yönelimli kültür tipinin (Quinn ve Spreitzer, 2001; Cameron ve Quinn, 1999; Quinn, 1988) yenilikçi iş davranışlarını etkilemesi mümkündür. Yeniliği destekleyen değerler ve normlar, yaratıcılık ve yenilikçiliği etkileyen özel davranış biçimleriyle kendini gösterir (Martins ve Terblanche, 2003: 72). Wei ve diğerlerine (2011: 22) göre, bir işletme gelişime yönelimli bir kültür yapısına sahip ise; çalışanların yeni kaynaklar kazanma, girişimci faaliyetler gösterme ve yaratıcı yöntemlerle problemleri tanımlama ve çözme yönünde hareket etmeleri ve davranışlar sergilemeleri beklenebilir.

Yapılan araştırmalarda örgütte algilanan gelişim yönelimli kültür tipinin örgütün yenilikçiliğini (Duygulu ve Özeren, 2009) ve 
çalışanların yenilikçi davranışlarını artırdığını ortaya konulmuştur (Akkoç ve diğ., 2011; Schepers ve Berg, 2007). Örneğin, Schepers ve Berg (2007); örgütte yenilik, dişa uyum, gelişim ve kaynak kazanımına önem veren kültür tipini algılayan çalışanların, çalışma ortamlarını yaratıcı olarak algıladıklarını ve daha yüksek düzeyde bilgi paylaşma yönünde davranışlar sergilediğini belirlemiştir. Scott ve Bruce (1994) algılanan yaratıcı örgüt ikliminin yenilikçi iş davranışlarını artırdığını tespit etmiştir. Miron ve diğerleri (2004) risk alan ve toleransa açık bir yenilikçi kültürün bireylerin yenilikçi performansını artırdığını belirlemiş̧tir.

Yukarıdaki açıklamaların ışığı altında, algılanan bağlılık tabanlı insan kaynakları sisteminin algılanan gelişim kültürünün aracılığıyla çalışanların yenilikçi iş davranışlarını etkileyebileceği beklenebilir. Örneğin, bağlllığı artırma yönünde etki gösterebilecek uygulamalardan biri olan ödülllendirme sistemleri, risk almayı vurgulayan bir kültürün oluşumunu destekleyebilir, çalışanların yaratıcı davranışlarını teşvik edebilir (Shalley ve Gilson, 2004; Amabile ve diğg., 1996; Gundry ve diğ., 1994; Woodman ve diğ., 1993).

$\mathrm{Bu}$ açıklamalara dayalı olarak aşağıdaki hipotez geliştirilmiştir:

Hipotez 2: Algılanan bağlllık tabanlı insan kaynakları sistemi ile yenilikçi iş davranışı arasındaki ilişkide, gelişim kültürünün aracılık etkisi vardır.

\section{Araştırmanın Yöntemi}

\subsection{Araştırmanın Evreni ve Örneklemi}

Araştırma, Bursa'da taşıt araçları imalat endüstrisine parça üreten altı işletmede yapılmıştır. İnsan kaynakları yönetimi yazınındaki öneriler doğrultusunda belirli bir sektöre odaklanarak gerçekleştirilen araştırmayla sektöre özgü farklılıklar kontrol altına alınmaya çalışılmıştır. Bu bağlamda, Jackson ve Schuler (1995), imalat ve hizmet sektörlerinde insan kaynakları sistemlerinin yapılanması ve benimsenen örgüt kültürü tiplerinin farklılıklar gösterebileceğini belirtmiştir.
Araştırmanın evrenini altı işletmede görev yapan toplam 348 beyaz yakalı çalışan oluşturmuştur. Beyaz yakalı çalışan sayısı ile ilgili bilgiler, araştırma kapsamındaki işletmelerde bu bilgiye erişebilen yöneticilerle görüşülerek elde edilmiştir. Araştırmanın örneklemi ise, dağıtılan soru formlarını dolduran toplam 156 beyaz yakalı çalışandan meydana gelmektedir. Toplam soru formu geri dönüş oranı \% 44,8'tür. Bu formlar arasından eksik doldurulan soru formları çıkarılarak, geriye kalan 121 soru formu analizlere dahil edilmiştir. Kullanılabilir soru formu geri dönüş oranı \% 34,8 olarak belirlenmiştir. Bu oran, benzer konularda yapılan uluslararası yayınlar değerlendirildiğinde, normal düzeyde geri dönüş oranı olarak kabul görmektedir.

Araştırmaya katılanların demografik verileri incelendiğinde, işletmelerin sektöre özgü istihdam yapısından dolayı erkek ağırlıklı çalışan istihdam ettiği; örneklemin \% 37,2'sinin kadın, \% 62,8'inin erkek çalışandan oluştuğu belirlenmiştir. Katılımcıların \% 11,6'sı 19-25, \% 57,9'u 25-34, \% 20,7'si 35-44, \% 9,1'i $45-54$ ve \% 0,8'i 55-64 yaş aralığındadır. \% $19,9^{\prime}$ unun orta ve lise öğretimi düzeyinde, \% $14,9^{\prime}$ unun önlisans düzeyinde, \% 54,5'inin lisans düzeyinde, \% 9,1'inin yüksek lisans düzeyinde ve \% 1,7'sinin doktora düzeyinde eğitime sahip olduğu görülmüştür. Çalışanların kurumda geçen hizmet süresine ilişkin dağılımları değerlendirildiğinde ise; en fazla çalışma süresinin $\% 61,2$ oranıyla 5 yıl ve altında kıdeme sahip olan çalışanlar olduğu belirlenmiştir.

Araştırmada kullanılan değişkenlerin tek bir kaynağın (beyaz yakalı çalışanlar) algilarına dayalı bilgilerle elde edilmesi nedeniyle (Podsakoff ve Organ, 1986), benzer araştırmalarda olduğu gibi, bu araştırmada da ortak yöntem varyansı eğilimiyle ilgili olasılık söz konusudur. Ortak yöntem varyansının bir sorun oluşturup oluşturmadığını belirlemek için, yaygın bir şekilde kullanılan istatistiksel prosedürlerden biri olan Harman'ın tek-faktör testi yapılmıştır (Podsakoff ve Organ, 1986). $\mathrm{Bu}$ bağlamda, araştırmada kullanılan tüm ölçek maddelerine faktör analizi uygulanmıştır. Döndürülmemiş faktör analizi sonucuna göre, tek bir faktörün ortaya 
çıkmadığ 1 ve birinci faktörün toplam varyansın yalnızca \% 32'sini açıkladığı tespit edilmiştir. Elde edilen sonuçlar, veri setinde ortak yöntem varyansının önemli bir sorun oluşturmadığını göstermektedir.

\subsection{Araştırmanın Ölçekleri}

Araştırma değişkenlerinin ölçümünde bağlılık tabanlı insan kaynakları uygulamaları, gelişim kültürü ve yenilikçi iş davranışı ölçeklerinden yararlanılmıştır. Ölçeklerin çevirisi, iki ayrı çift dilli uzman tarafından İngilizce' den Türkçe'ye çeviri ve Türkçe'den İngilizce'ye geri çeviri yöntemi ile gerçekleşmiş, maddelerin çevirisi ile orijinali çift dilli bir uzmanın kontrolünden geçerek düzenlenmiştir.

\subsubsection{Bağlılık Tabanlı Insan Kaynakları} Sistemi Ölçeği: Bağlılık tabanlı insan kaynakları sisteminin ölçümünde Lepak ve Snell (2002, 1999)'in geliştirdiği bağlllik tabanlı insan kaynakları uygulamalarını içeren yirmi ifadelik ölçek kullanılmıştır. Bu ölçekte sorular "Eğitim faaliyetleri kapsamlıdır", "Performans değerlemeleri çalışanın gelişimini amaçlayan geri bildirim içerir" şeklindedir. Cevap ölçeği 5'li Likert ölçeği (1=Kesinlikle Katılmıyorum, $5=$ Kesinlikle katiliyorum) olarak belirlenmiştir.

Stratejik insan kaynakları yönetimi alanında yapılan uluslararası çalışmalardan yola çıarak (Lepak ve Snell, 2002; Becker ve Huselid, 1998; Huselid, 1995), bağlılık tabanlı insan kaynakları sistemi endeks olarak tanımlanmıştır. Jarvis ve diğerlerinin (2003) belirttiği gibi, endeksleri oluşturan maddeler grubu genel yapınin teorik anlamını birlikte belirlemektedir. Bu doğrultuda, bağlılık tabanlı insan kaynakları sistemi; iş tasarımı, işe alma ve seçme, eğitim ve geliştirme, performans değerleme ve ücretlendirmeyi içeren bağlılık tabanlı insan kaynakları uygulamalarını (Lepak ve Snell, 2002, 1999) oluşturan maddelerin toplamını ifade etmektedir. Çeşitli araştırmacıların endekslerin değerlendirilmesiyle ilgili önerileri doğrultusunda (Jarvis ve diğg., 2003; Diamantopoulos ve Winklhofer, 2001), ölçeklere uygulanan güvenilirlik ve geçerlilik analizleri, endeks olarak değerlendirilen bağlılık tabanlı insan kaynakları sistemine uygulanmamıştır.

\subsubsection{Gelişim Kültürü Ölçeği:} Algılanan gelişim kültürünün ölçümünde Quinn ve Spreitzer (2001)'in geliştirdiği, Wei ve diğerleri (2008) tarafindan kullanılan şirket kültürü ölçeğinden yararlanılmış, gelişim kültürünü ölçmek için dört ifadelik ölçek kullanılmıştır. Ölçekteki ifadeler "Şirketimiz çok dinamik ve girişimci bir kurumdur", "Şirketimizi bir arada tutan bağlar yenilikçilik ve gelişmeye olan bağl1lıktır" şeklindedir. 5'li Likert ölçeği formundadır (1=Çok düşük, $5=$ Çok yüksek). Gelişim kültürü ölçeğinin güvenilirlik katsayısı .85 olarak bulunmuştur. Ölçek güvenilirliğinin yüksek düzeyde olduğu görülmektedir (Nunnally, 1978).

Gelişim kültürü ölçeğine temel bileşenler analizi yöntemiyle uygulanan faktör analizi sonucunda, dört maddeyi kapsayan ve özdeğeri 1'den büyük olan tek faktör elde edilmiştir. Veri setinin faktör analizine uygunluğunu belirlemek için yapılan testler sonucunda, gelişim kültürü ölçeğinin Kaiser-Meyer-Olkin (KMO) örneklem yeterliliği ölçütü .81 olarak bulunmuştur. Bartlett küresellik testi (Bartlett's Test of Sphericity) ise, istatistiksel olarak anlamlidir $(\mathrm{p}<.001)$. Bulunan tek faktör, toplam varyansin \% 69.06'sını açıklamaktadır. KMO oranının $0.5^{\prime}$ in üzerinde bulunması ve Bartlett testi sonucunun anlamlı olması veri setinin faktör analizine uygun olduğunu göstermektedir (Kalaycl, 2008). 


\subsubsection{Yenilikçi İş Davranışı Ölçeği:} Yenilikçi iş davranışının ölçümünde ise, dokuz ifadelik ölçekten yararlanılmıştır (Janssen, 2000). Ölçekteki maddeler "Problemler için orijinal çözümler üretmek", "Yenilikçi fikirler için onay almak", "Yenilikçi fikirleri yararlı uygulamalara dönüştürebilmek" şeklindedir. 5'li Likert ölçeği (1=Hiçbir zaman, 5=Her zaman) kullanılmıştır. Yenilikçi iş davranışı ölçeğine ilişkin güvenilirlik katsayısı .93 olarak belirlenmiştir. Ölçeğin güvenilirliği yüksek düzeydedir (Nunnally, 1978).

Janssen (2000)'in yaklaşımı doğrultusunda, yenilikçi iş davranışının üç alt boyutunun (fikir üretme, fikir tanitımı ve fikir uygulama) kendi aralarındaki ilişkiler, korelasyon analiziyle değerlendirilmiştir. Ele edilen korelasyonların sonuçları şöyledir: Fikir üretme ile fikir uygulama $(r=$ $.68 ; \mathrm{p}<.01)$, fikir üretme ile fikir tanıtımı $(\mathrm{r}=$ .77; $\mathrm{p}<.01)$, fikir tanitımı ile fikir uygulama $(\mathrm{r}=.78 ; \mathrm{p}<.01)$. Analiz sonucuna göre, alt boyutlar arasındaki korelasyonların pozitif ve anlamlı ilişkiler gösterdiği görülmüştür. Elde edilen korelasyonlar ile Janssen (2000, 2004)'in bulguları arasında yakınlık görülmektedir.

Yenilikçi iş davranışı ölçeğine temel bileşenler analizi yöntemiyle faktör analizi uygulanmıştır. Ölçek için yapılan faktör analizi sonucunda, 9 maddeyi içine alan ve özdeğeri 1'in üzerinde olan tek faktör tanımlanmıştır. Bu ölçeğin Kaiser-MeyerOlkin (KMO) örneklem yeterliliği ölçütü; .92'dir. Bartlett küresellik testinin sonucu ise, istatistiksel olarak anlamlı $(\mathrm{p}<.001)$ belirmiştir. Bu faktör, toplam varyansın \% 65.86'sını açıklamaktadır. Sonuç olarak, KMO oranının $0.5^{\prime}$ in üzerinde bulunması ve Bartlett testi sonucunun anlamlı olması nedeniyle, veri seti faktör analizine uygun olarak değerlendirilmiştir (Kalaycı, 2008).
Janssen (2000)'in önerileri doğrultusunda yapılan korelasyon analizi sonucunda ve faktör analizinin sonucunda ölçeğin tek faktör olarak belirlenmesi nedeniyle, yenilikçi iş davranışı ölçeği üç alt boyut birleştirilerek test edilmiştir.

3.2.4. Kontrol Değişkenleri: İlgili yazında yapılan benzer çalışmalarda yaş ve cinsiyetin yenilikçi iş davranışıyla ilişkili olduğu bulgusundan hareket edilmiş $(\mathrm{Ng}$ ve Feldman, 2012; Janssen, 2005; Janssen, 2000), istatistiksel analizlere yaş ve cinsiyet kontrol değişkeni olarak eklenmiştir. Yaş değişkeninin beş kategoriye ayırılmış olması nedeniyle, kukla (dummy) değişkenler haline dönüştürülerek analizlere dahil edilmiştir. 25-34 yaş aralığındaki grup baz kategorisi (kontrol grubu) olarak belirlenmiştir (2534 yaş aralığ $1=0$ ). Her biri baz kategorisiyle kıyaslanan dört kategori (k1) oluşturulmuştur. Bunlar; Yaş1 (19-25 yaş aralığ $)=1$, Yaş2 (35-44 yaş aralığ1) = 1, Yaş3 (45-54 yaş aralığı) = 1, Yaş4 (55-64 yaş aralığ 1$)=1$ olarak kodlanmıştır.

\section{Bulgular}

Araştırma verileri, SPSS 20.0 istatistik paket programında çözümlenmiştir. İlk adımda araştırmada kullanılan ölçeklere güvenilirlik, geçerlilik ve faktör analizi yapılmıştır. Bu ölçekler, ilgili yazında çeşitli araştırmacılar tarafından güvenilirlik ve geçerlilik analizleri yapılarak sınanmış ölçekler olsa da, bu araştırmada yeniden analize tabi tutulmuştur. İkinci adımda; bağlılık tabanlı insan kaynakları sistemi, gelişim kültürü, yenilikçi iş davranışı ve kontrol değişkenlerine ilişkin elde edilen verilerin ortalamaları, standart sapmaları ve korelasyonları incelenmiştir. Analizler sonucunda elde edilen bulgular Tablo 1'de sunulmuştur. Son adımda ise, araştırma hipotezlerini test etmek amaciyla hiyerarşik regresyon analizi yapılmış, analiz sonuçları tablolara aktarıldıktan sonra yorumlanmıştır (Tablo 2). 


\section{Tablo 1}

Araştırma Değişkenlerine İlişkin Ortalama, Standart Sapma ve Korelasyon Değerleri

\begin{tabular}{llllllllll}
\hline & Ort. & S.S. & $\mathbf{1}$ & $\mathbf{2}$ & $\mathbf{3}$ & $\mathbf{4}$ & $\mathbf{5}$ & $\mathbf{6}$ & $\mathbf{7}$ \\
\hline 1. Yenilikçi İş Davranış1 & 3.66 & .72 & & & & & & & \\
2. Yaş1 & .12 & .32 & -.05 & & & & & & \\
3. Yaş2 & .21 & .41 & .13 & $-.19^{*}$ & & & & & \\
4. Yaş3 & .09 & .29 & -.18 & -.11 & -.16 & & & & \\
5. Yaş4 & .01 & .09 & .06 & -.03 & -.05 & -.03 & & & \\
6. Cinsiyet & 1.63 & .49 & -.01 & -.15 & $.18^{*}$ & .07 & .07 & & \\
7. Gelişim Kültürüi & 3.72 & .78 & $.58^{* *}$ & .08 & .06 & -.03 & .12 & -.16 & \\
8. Bağl1lk Tabanlı İKS & 67.78 & 10.95 & $.45^{* *}$ & .09 & -.03 & .13 & .12 & -.00 & $.57^{* *}$ \\
\hline${ }^{*} \mathrm{p}<.05,{ }^{* *} \mathrm{p}<.01$ & & & & & & & & &
\end{tabular}

${ }^{*} \mathrm{p}<.05, \mathrm{p}$ p $<.01$

Tablo 1'de araştırmada kullanılan tüm değişkenler için ortalama, standart sapma ve korelasyonlara ilişkin sonuçlar verilmiştir. Korelasyon analizi sonucuna göre, algılanan bağlılık tabanlı insan kaynakları sistemi $(\mathrm{r}=.57$; $\mathrm{p}<.01)$, algilanan gelişim kültürü ile pozitif ve anlamlı ilişki göstermektedir. Aynı şekilde, algılanan bağlılık tabanlı insan kaynakları sistemi $(\mathrm{r}=.45 ; \mathrm{p}<.01)$ ve algılanan gelişim kültürü $(\mathrm{r}=.58 ; \mathrm{p}<.01)$, sonuç değişkeni olan yenilikçi iş davranışı ile pozitif ve anlamlı ilişki sergilemektedir.

Tablo 2

Hiyerarşik Regresyon Analizi Sonuçları

\begin{tabular}{|c|c|c|c|}
\hline & \multirow{2}{*}{$\begin{array}{c}\text { Gelişim } \\
\text { Kültürüu } \\
\text { 1. Model } \\
\beta \\
\end{array}$} & \multicolumn{2}{|c|}{$\begin{array}{c}\text { Yenilikçi } \\
\text { İş Davranışı }\end{array}$} \\
\hline & & $\begin{array}{c}\text { 2. Model } \\
\beta \\
\end{array}$ & $\begin{array}{c}\text { 3. Model } \\
\beta\end{array}$ \\
\hline Yaş1 & .02 & -.11 & -.12 \\
\hline Yaş2 & .11 & .10 & .05 \\
\hline Yaş 3 & -.07 & $-.23^{*}$ & $-.20^{*}$ \\
\hline Yaş 4 & .07 & -.01 & -.04 \\
\hline Cinsiyet & $-.17^{*}$ & -.03 & .05 \\
\hline Bağlılık Tabanlı İKS & $.57^{* *}$ & $.49^{* *}$ & $.22^{*}$ \\
\hline Gelişim Kültürüu & & & $.47^{* *}$ \\
\hline $\mathbf{R}^{2}$ & .37 & .28 & .42 \\
\hline Düzeltilmiş $\mathbf{R}^{2}$ & .34 & .24 & .38 \\
\hline $\mathbf{F}$ & $11.25^{* *}$ & $7.26^{* *}$ & $11.55^{* *}$ \\
\hline
\end{tabular}

${ }^{*} \mathrm{p}<.05,{ }^{* *} \mathrm{p}<.001$ 
Hipotezleri test etmek amaciyla yapılan hiyerarşik regresyon analizinde kontrol değişkenleri (yaş ve cinsiyet), algılanan bağlllık tabanlı insan kaynakları sistemi, algılanan gelişim kültürü ve yenilikçi iş davranışı modele dahil edilmiştir (Tablo 2). Algılanan gelişim kültürünün, algılanan bağlılık tabanlı insan kaynakları uygulamaları ile yenilikçi iş davranışı arasındaki ilişkide aracılık etkisini test etmek için Baron ve Kenny (1986)'nin aracılık analiz tekniği kullanılarak, önerilen adımlarla hiyerarşik regresyon analizi yapılmıştır.

Tablo 2'de hiyerarşik regresyon analizinin sonuçları verilmiştir. Bu sonuçlara göre, kurulan modellerin istatistiksel olarak anlamlı olduğu görülmektedir (sirasiyla $F=11.25 ; \quad F=7.26$; F=11.55; $\mathrm{p}<$.001). Birinci adımda (1. Model), analize kontrol değişkenleri (yaş ve cinsiyet) ve bağımsız değişken (algılanan bağlılık tabanlı insan kaynakları sistemi) eklenmiş; algılanan bağlılık tabanlı insan kaynakları sisteminin algılanan gelişim kültürü üzerinde $(\beta=.57, \mathrm{p}<$ .001) istatistiksel olarak pozitif ve anlaml bir etkisinin olduğu ortaya çıkmıştır. Bu sonuca göre, H1 hipotezi kabul edilmiştir. Cinsiyet ve algılanan gelişim kültürü $(\beta=-.17 ; p<.05)$ arasında negatif yönde ve anlamlı bir ilişki görülmüştür. Analizin ikinci adımında (2. Model), bağımsız değişken (algılanan bağlılık tabanlı insan kaynakları sistemi) ile bağımlı değişken (yenilikçi iş davranışı) arasındaki ilişki incelenmiş; algılanan bağlılık tabanlı insan kaynakları sistemi ile yenilikçi iş davranışı arasinda $(\beta=.49, \mathrm{p}<.001)$ pozitif ve anlaml bir ilişki belirlenmiştir. Ayrıca kontrol değişkenlerinden Yaş3 ile yenilikçi iş davranışı $(\beta=-.23 ; p<.05)$ arasında negatif yönde ve anlamlı bir ilişki görülmüştür. Üçüncü adımda (3. Model) ise, bağımsız değişken (algılanan bağlılık tabanlı insan kaynakları sistemi) ve aracı değişken (algılanan gelişim kültürü) ile bağımlı değişken (yenilikçi iş davranışı) analize aynı anda dahil edilmiştir. 3. Modelde, algilanan gelişim kültürünün yenilikçi iş davranışı üzerinde $(\beta=.47 ; \mathrm{p}<.001)$ pozitif ve anlamlı bir etki gösterdiği ortaya çıkmıştır. Bununla beraber, 2. Modeldeki algilanan bağlllık tabanlı insan kaynakları sistemi ile yenilikçi iş davranışı ilişkisindeki regresyon katsayısının $(\beta=.49 ; \mathrm{p}<$
.001); 3. Modelde, algılanan gelişim kültürü kontrol altına alındığında azalma göstermesine rağmen $(\beta=.22 ; p<.05)$, ilişkinin anlamlılığını sürdürdüğü belirlenmiştir. Baron ve Kenny (1986)'nin aracilık analiz tekniğine göre yorumlandığında, bu sonuç algılanan gelişim kültürünün algılanan bağlılık tabanlı insan kaynakları sistemi ile yenilikçi iş davranışı arasında kısmi aracilık etkisine sahip olduğunu göstermektedir. H2 hipotezi reddedilmiştir. Ayrıca bu adımda da, Yaş3 ile yenilikçi iş davranışı $(\beta=-.20 ; \mathrm{p}<.05)$ arasında negatif yönde ve anlamlı bir ilişki ortaya çıkmıştır. Model 2 ve 3'te elde edilen sonuçlara göre, 45-54 yaş aralığındaki çalışanlar, 25-34 yaş aralığındaki çalışanlara kıyasla daha az yenilikçi iş davranışı sergilemektedir.

\section{Tartışma ve Sonuç}

Bu çalışma ile Bursa'da taşıt araçları imalat endüstrisine parça üreten işletmelerde görev yapan çalışanların algıladığı bağlılık tabanlı insan kaynakları sisteminin gelişim kültürüne ilişkin algılarına ve yenilikçi iş davranışlarına etkisi araştırılmıştır. Araştırmanın yapıldığı endüstri dalına ilişkin olarak insan kaynakları sistemi ile çalışan davranışları ilişkisini açıklayan önemli bulgular elde edilmiştir. Bulgular, bağlılık tabanlı insan kaynakları sistemlerinin belirli bir sektörde yenilikçi iş davranışlarını etkileme nedenlerini aydınlatıcı bilgiler vermektedir.

Çalışmanın bulgularına göre, algılanan bağlılık tabanlı insan kaynakları sisteminin algilanan gelişim kültürü üzerinde pozitif ve anlamlı bir etkisi olduğu görülmüştür. Elde edilen bulgu bu alanda yapılan çalışmalarla uyumlu bir çizgide görülmektedir. İnsan kaynakları yazınında bağlılığı artırmaya yönelimli olarak yapılandırılmış insan kaynakları sistemlerinin kültür şekillendirici rolü irdelenmiştir (Wei ve diğ., 2011; Hartog ve Verburg, 2004; Lau ve Ngo, 2004). Bu yönde yapılanan insan kaynakları sistemleri yenilikçilik ve girişimcilik gibi değerlere önem veren bir kültürün oluşumunu sağlayabilir (Hartog ve Verburg, 2004; Lau ve Ngo, 2004). Robert ve Wasti (2002)'nin Türk işletmelerinde 
yaptığ 1 bir araştırmada vurguladığı gibi, belirli varsayımlar ve değerleri temel alan insan kaynakları uygulamaları örgütün kültürüne yönelik çalışanların ortak algılarını anlamada önemli bir rol oynar. Bu açıklamaların ışığı altında, çalışanların bağlılık tabanlı insan kaynakları sistemi aracılığıyla gelişimi destekleyici bir örgüt kültürünü algılaması, anlaması ve deneyimlemesi söz konusudur.

Elde edilen diğer bir bulgu ise, algılanan bağlılık tabanlı insan kaynakları sistemi ile yenilikçi iş davranışı arasındaki ilişkide gelişim kültürünün kısmi aracılık etkisi olduğunu göstermektedir. Bu bulgu, gelişim kültürünün tam aracılık etkisine ilişkin geliştirilen hipotezi desteklememektedir. Araştırmanın bulguları algılanan bağlılık tabanlı insan kaynakları sisteminin yenilikçi iş davranışı üzerinde doğrudan etkisi olduğuna da işaret etmektedir. İlgili yazında yer alan bazı çalışmalar bağlılığı artırmayı sağlayabilecek çeşitli insan kaynakları uygulamalarının çalışanların yenilikçi iş davranışları sergilemesinde etkili olduğunu vurgulamaktadır (Erdil ve diğ., 2004; West ve diğ., 2004; Egan, 2005; Fernandez ve Pitz, 2011). Örneğin, Erdil ve diğerlerinin (2004) imalat işletmelerinde yaptığ zenginleştirme, iş genişletme ve personel seçim sürecinin çalışanların yenilikçilik eğilimi üzerinde olumlu etki gösterdiği ortaya çıkmıştır.

Ulaşılan bulgular, algılanan bağlılık tabanlı insan kaynakları sistemi ile yenilikçi iş davranışı ilişkisinde rol oynayan nedensel ilişkilere ş̧ık tutmaktadır. Araştırmanın bulguları, kısmi aracılık etkisi gösteren gelişim kültürünün nedensel ilişkiyi açılayan bir role sahip olduğunu ortaya koymuştur. Bağlllık tabanlı insan kaynakları uygulamaları çalışanların beceri ve yeteneklerinin geliştirilmesine odaklı bir istihdam anlayışını ve uzun vadeli çalışan bağlılığını amaçlamaktadır (Lepak ve Snell; 2002, 1999). Bu açıdan değerlendirildiğinde, insan kaynakları sistemlerinin arzu edilen amaçlara yönelik çalışanların algılarını ve davranışlarını yönlendirmede ve benzer davranışları sergilemelerinde etkili olması söz konusudur (Bowen ve Ostroff, 2004). Yenilikçilik, büyüme, gelişme ve risk almaya önem veren gelişime yönelimli bir kültürün (Denison ve Spreitzer, 1991) algilanması, çalışanların bu kültürü destekleyen davranışları sergilemelerinde işletmenin kendilerini cesaretlendirme ve onaylama yönünde hareket ettiğine inanmalarını ve güven duymalarını sağlayabilir. Bu durum, çalışanların yenilikçi davranışları sergileme yönünde motive olmalarını ve bu davranışları daha fazla göstermelerini özendirici bir rol oynayabilir. Çekmecelioğlu (2006)'nun sanayi işletmelerinde yaptığı bir araştırmada, yaratıcılığ1 destekleyen bir örgüt ikliminin çalışanların yaratıcılığını artıran bir etki gösterdiği sonucuna ulaşılmıştır. İşletmeler örgüt kültürünün yaratıcılık, yenilikçilik, risk alma, değişime açıklık gibi girişimcilik özelliklerini artırarak daha yaratıcı ve yenilikçi bir işgücüne sahip olabilir (Öktem ve diğ., 2003).

Algılanan bağlılık tabanlı insan kaynakları sistemi ile yenilikçi iş davranışı arasındaki ilişkide gelişim kültürünün kısmi aracılık etkisi göstermesi, bu nedensel ilişkiyi açıklayan başka aracıların varlığını da gösterebilir. Örneğin, psikolojik sözleşmeler (Ramamoorthy ve diğ., 2005; Uen ve diğ., 2009) ve sosyal örgüt iklimi (Collins ve Smith, 2006) bu ilişkide aracılık rolü oynayabilir.

Elde edilen bulguların yanı sıra, araştırmanın bazı sınırlılıkları mevcuttur. Araştırma belirli bir sektörde gerçekleştirilmiştir. Dolayısıyla, araştırmanın bulguları belirli bir sektöre yönelik açıklayıcı bilgiler vermektedir. İnsan kaynakları yönetimi yazınında bağllık tabanlı insan kaynakları sistemlerinin etkileri incelenirken belirli bir sektöre odaklanmak gerektiği önerilmiştir (McDuffie, 1995; Collins ve Smith, 2006). Ancak, çeşitli sektörlerden elde edilen bulguların karşılaştırılarak sektöre özgü etkilerin olup olmadığını tespit etmek amacıyla, bundan sonra gerçekleştirilecek araştırmaların farklı sektörler dahil edilerek tekrarlanması önerilmektedir. Ayrıca tek bir kültür tipinin ele alınması da diğer bir kısıt olarak görülebilir. $\mathrm{Bu}$ çalışmada insan kaynakları yazınında yapılan incelemelere dayalı olarak, bağlılık tabanlı insan kaynakları sistemi gelişim kültürü ile ilişkili olarak değerlendirilmiştir. Bundan sonra yapılacak araştırmalarda diğer örgüt tipleri de dahil 
edilerek, bağlılık tabanlı insan kaynakları sistemlerinin farklı örgüt tiplerine ve sonrasında çalışanların davranışlarına yönelik etkileri ve nedenleri ortaya çıkarılabilir. Ayrıca algılanan bağlılık tabanlı insan kaynakları sistemi ile yenilikçi iş davranışı arasındaki ilişkide gelişim kültürünün kısmi aracilık etkisi göstermesi nedeniyle, ileride yapılacak araştırmalarda diğer aracılar da dahil edilerek etkiler incelenebilir. Yapılan çalışmanın kesitsel bir araştırma olması, diğer bir kısıt olarak da değerlendirilebilir. İleride gerçekleştirilecek araştırmalarda boylamsal tipte bir araştırma yapılarak nedensel ilişkiler ve aracılık etkileri incelenebilir.

Sonuç olarak, bu araştırmanın bulgularının bağlılık tabanlı insan kaynakları sistemlerinin çalışanların davranışlarını etkileme nedenlerine ilişkin açıklamalar getirerek insan kaynakları yönetimi yazınına katkıda bulunduğu düşünülmektedir. 


\section{Kaynakça}

Akkoç, İ., Turunç, Ö. ve Çalışkan, A. (2011). Gelişim Kültürü ve Lider Desteğinin Yenilikçi Davranış ve İş Performansına Etkisi: İs-Aile Çatışmasının Aracılık Rolü. "İş, Güç" Endüstri İlişsileri ve İnsan Kaynakları Dergisi, 13: 4, s. 83-114.

Akkoç, İ., Çalışkan, A. ve Turunç, Ö. (2012a). Örgütlerde Gelişim Kültürü ve Algılanan Örgütsel Desteğin İş Tatmini ve İş Performansına Etkisi: Güvenin Aracllık Rolü. Yönetim ve Ekonomi, 19:1, 105-135.

Akkoç, İ., Çalışkan, A. ve Turunç, Ö. (2012b). Örgüt Kültürünün Girişimciliğe Etkisinde Öz Yeterliliğin Düzenleyici Rolü. "İş, Güç" Endüstri İlişkileri ve İnsan Kaynakları Dergisi, 14: 3, 19-42.

Amabile, T. M., Conti, R., Coon, H., Lazenby, J. ve Herron, M. (1996). Assessing the Work Environment for Creativity. Academy of Management Journal, 39: 5, 1154-1184.

Arthur, J. B. (1994). Effects of Human Resource Systems on Manufacturing Performance and Turnover. The Academy of Management Journal, 37: 3, 670-687.

Arthur, J. B. (1992). The Link between Business Strategy and Industrial Relations Systems in American Steel Minimills. Industrial and Labor Relations Review, 45: 3, 488-506.

Axtell, C. M., Holman, D. J., Unsworth, K. L., Wall, T. D., Waterson, P. E. ve Harrington, E. (2000). Shopfloor Innovation: Facilitating the Suggestion and Implementation of Ideas. Journal of Occupational and Organizational Psychology, 73, 265-285.

Barney, J. B. ve Wright, P. M. (1998). On Becoming a Strategic Partner: The Role of Human Resources in Gaining Competitive Advantage. Human Resource Management, 1998, 37: 1, 3146.

Baron, R. M. ve Kenny, D. A. (1986). The Moderator-Mediator Variable Distinction in Social Psychological Research: Conceptual, Strategic, and Statistical Considerations. Journal of
Personality and Social Psychology, 51: 6, 1173-1182.

Becker, B. E. ve Gerhart, B. (1996). The Impact of Human Resource Management on Organizational Performance: Progress and Prospects. The Academy of Management Journal, 39: 4, 779-801.

Becker, B. E. ve Huselid, M. A. (1998). High Performance Work Systems and Firm Performance: A Synthesis of Research and Managerial Implications. Research in Personnel and Human Resources Management, 16, 53-101.

Becker, B. E. ve Huselid, M. A. (2006). Strategic Human Resources Management: Where Do We Go From Here? Journal of Management, 32, 898-925.

Bowen, D. E. ve Ostroff, C. (2004). Understanding HRM-Firm

Performance Linkages: The Role of the "Strength" of the HRM System. Academy of Management Review, 29: 2, 203-221.

Cabrera, E. F. ve Bonache, J. (1999). An Expert HR System for Aligning Organizational Culture and Strategy. Human Resource Planning, 51-60.

Cameron, K. S. ve Quinn, R. E. (1999). Diagnosing and Changing Organizational Culture. Reading: Addison-Wesley.

Ceylan, C. (2013). Commitment-Based HR Practices, Different Types of Innovation Activities and Firm Innovation Performance. The International Journal of Human Resource Management, 24:1, 208-226, DOI:10.1080/09585192.2012.680601.

Version of record first published: 18 Apr 2012.

Chan, L. L. M., Shaffer, M. A. ve Snape, E. (2004). In Search of Sustained Competitive Advantage: The Impact of Organizational Culture, Competitive Strategy and Human Resource Management Practices On Firm Performance. The International Journal of Human Resource Management, 15:1, 17-35. 
Chang, E. (2005). Employees' Overall Perception of HRM Effectiveness. Human Relations, 58: 4, 523-544.

Collins, C. J. ve Smith, K. G. (2006). Knowledge Exchange and Combination: The Role of Human Resource Practices in the Performance of High-Technology Firms. Academy of Management Journal, 49: 3, 544-560.

Çekmecelioğlu, H. G. (2006). Örgüt İklimi, Duygusal Bağlılık Ve Yaratıcilık Arasındaki İlişkilerin Değerlendirilmesi: Bir Araştırma. Atatürk Üniversitesi İktisadi ve İdari Bilimler Fakültesi Dergisi, 20: 2, 295- 311.

Delery, J. E. ve Doty, D. H. (1996). Modes of Theorizing in Strategic Human Resource Management: Tests of Universalistic, Contingency, and Configurational Performance Predictions. The Academy of Management Journal, 39: 4, 802-835.

Denison, D. R. ve Spreitzer, G. M. (1991). Organizational Culture and Organizational Development: A Competing Values Approach. Research in Organizational Change and Development, 5, JAI Press, s. 1-21.

Diamantopoulos, A. ve Winklhofer, H. M. (2001). Index Construction with Formative Indicators: An Alternative to Scale Development. Journal of Marketing Research, 38: 2, 269-277.

Dorenbosch, L., Van Engen, M. L. ve Verhagen, M. (2005). On-the-job Innovation: The Impact of Job Design and Human Resource Management through Production Ownership. Creativity and Innovation Management, 14: 2, 129-141.

Duygulu, E. ve Ozeren, E. (2009). The Effects of Leadership Styles and Organizational Culture on Firm's Innovativeness. African Journal of Business Management, 3: 9, 475-485.

Egan, T. M. (2005). Factors Influencing Individual Creativity in the Workplace: An Examination of Quantitative Empirical Research. Advances in Developing Human Resources, 7: 2, 160181.
Erdil, O., Alpkan, L. H. ve Biber, L. (2004). İnsan Kaynakları Uygulamalarıyla Örgütsel Performans Arasındaki İlişkileri Araştırmaya Yönelik Bir İnceleme. D.E.Ü. İ.İ.B.F.Dergisi, 19:2, 101-122

Eroğlu, A. (2008). Faktör analizi, SPSS Uygulamalı çok değişkenli istatistik teknikleri. Editör: Şeref Kalayc1, 3. Baskı, Ankara, Asil Yayın Dağıtım, s. 321-331.

Fernandez, S. ve Pitz, D. W. (2011) Understanding Employee Motivation to Innovate: Evidence from Front Line Employees in United States Federal Agencies. The Australian Journal of Public Administration, 70: 2, 202-222.

Gundry, L. K., Kickul, J. R. ve Prather, C. W. (1994). Building the Creative Organization. Organizational Dynamics, 22, 22-37.

Hartog, D. N. ve Verburg, R. M. (2004). High Performance Work Systems, Organisational Culture and Firm Effectiveness. Human Resource Management Journal, 14: 1, 55-78.

Huselid, M. A. (1995). The Impact of Human Resource Management Practices on Turnover, Productivity, and Corporate Financial Performance. Academy of Management Journal, 38: 3, 635-872.

Jackson, S. E., Schuler, R. S. ve Rivero, J. C. (1989). Organizational Characteristics as Predictors of Personnel Practices. Personnel Psychology, 42: 4, 727-786.

Jackson, S. E. ve Schuler, R. S. (1995). Understanding Human Resource Management in the Context of Organizations and Their Environments. Annual Review of Psychology. 46, 237-264.

Janssen, O. (2000). Job Demands, Perceptions of Effort - Reward Fairness and Innovative Work Behaviour. Joumal of Occupational and Organisational Psychology, 73, 287-302.

Janssen, O. (2004). How Fairness Perceptions Make Innovative Behavior More or Less Stressful. Journal of Organizational Behavior, 25, 201-215. 
Janssen, O. (2005). The Joint Impact of Perceived Influence and Supervisor Supportiveness on Employee Innovative Behaviour. Journal of Occupational and Organizational Psychology, 78, 573-579.

Jarvis, C. B., MacKenzie, S. B. ve Podsakoff, P. M. (2003). A Critical Review of Construct Indicators and Measurement Model Misspecification in Marketing and Consumer Research. Journal of Consumer Research, 30, 199-218.

Kayalar, M. ve Özmutaf, N. M. (2007). Gelişme Yönelimli Kurum Kültürü ile Yöneticinin Yönetsel Tutumları Arasındaki İlişkisellik: 100 Büyük Sanayi Kuruluşunda Bir Araştırma. Süleyman Demirel Üniversitesi İktisadi ve İdari Bilimler Fakültesi Dergisi, 12: 3, 163-176.

Krause, D. E. (2004). Influence-Based Leadership as a Determinant of the Inclination to Innovate and of Innovation-Related Behaviours. An Empirical Investigation. The Leadership Quarterly, 15, 79-102.

Kwon, K., Bae, J. ve Lawler, J. J. (2010). High Commitment HR Practices and Top Performers Impacts on Organizational Commitment. Management International Review, 50: 1, 57-80.

Lau, C. M., ve Ngo, H. Y. (1996). One Country Many Cultures: Organizational Culture of Firms of Different Country Origins. International Business Review, 5, 469486.

Lau, C. M. ve Ngo, H. Y. (2004). The HR System, Organizational Culture, and Product Innovation. International Business Review, 13, 685-703.

Laursen, K. ve Foss, N. J. (2003). New Human Resource Management Practices, Complementarities and the Impact on Innovation Performance. Cambridge Journal of Economics, 27, 243-263.

Lee, C. H. ve Bruvold, N. T. (2003). Creating Value for Employees: Investment in Employee Development. International Journal of Human Resource Management, 14: 6, 981-1000.

Lepak, D. P. ve Snell, S. A. (1999). The Human Resource Architecture: Toward a Theory of Human Capital Allocation and
Development. The Academy of Management Review, 24: 1, 31-48.

Lepak, D. P. ve Snell, S. A. (2002). Examining the Human Resource Architecture: The Relationships among Human Capital, Employment, and Human Resource Configurations, Journal of Management, 28: 4, 517-543.

Lepak, D. P., Liao, H., Chung, Y. ve Harden, E. E. (2006). A Conceptual Review of Human Resource Management Systems in Strategic Human Resource Management Research. Research in Personnel and Human Resources Management, 25, 217-271.

Lopez-Cabrales, A., Pérez-Luño, A. ve ValleCabrera, R. (2009). Knowledge as a Mediator between HRM Practices and Innovative Activity. Human Resource Management, 48: 4, 485- 503.

Martins, E. C. ve Terblanche, F. (2003). Building Organisational Culture That Stimulates Creativity and Innovation. European Journal of Innovation Management, 6: 1, 64-74.

McDuffie, J. P. (1995). HR Bundles and Manufacturing Performance: Organizational Logic and Flexible Production Systems in the World Auto Industry. Industrial \& Labor Relations Review, 48, 197-221.

Miron, E., Erez, M. ve Naveh, E. (2004). Do Personal Characteristics and Cultural Values that Promote Innovation, Quality, and Efficiency Compete or Complement Each Other? Journal of Organizational Behavior, 25, 175-199.

NG, T. W. H. ve Feldman, D. C. (2012). Age and Innovation-Related Behavior: The Joint Moderating Effects of Supervisor Undermining and Proactive Personality. Journal of Organizational Behavior, DOI: 10.1002/job.1802.

Nishii, L. H., Lepak, D. P. ve Schneider, B. (2008). Employee Attributions of the "Why" of HR Practices: Their Effects on Employee Attitudes and Behaviors, and Customer Satisfaction. Personnel Psychology, 61, 503-545. 
Nunnally, J. C. (1978). Psychometric theory (2nd ed.). New York: McGraw-Hill.

Öktem, M. K., Leblebici, D. N., Arslan, M., Kılıç, M. ve Aydın, M. D. (2003). Girişimci Örgütsel Kültür ve Çalışanların İç Girişimcilik Düzeyi: Uygulamalı Bir Çalışma. H. Ü. İktisadi ve İdari Bilimler Fakültesi Dergisi, 21:1, 169-188.

Palthe, J. ve Kossek, E. E. (2003). Subcultures and Employment Modes: Translating HR Strategy into Practice. Journal of Organizational Change Management, 16: 3, 287-308.

Podsakoff, P. ve Organ, D. (1986). Self-Reports in Organizational Research: Problems and Prospects. Journal of Management, 12, 531-544.

Quinn, R. E. (1988). Beyond Rational Management. San Francisco: JosseyBass.

Quinn, R. E., ve Spreitzer, G. M. (2001). The Psychometrics of the Competing Values Culture Instrument and an Analysis of the Impact of Corporate Culture on Quality of Life. Research in Organizational Change and Development, eds. R. W. Woodman and W. A. Pasmore, Greenwich, CT: JAI Press, s. 115-142.

Ramamoorthy, N., Flood, P. C., Slattery, T. ve Sardessai, R. (2005). Determinants of Innovative Work Behaviour: Development and Test of an Integrated Model. Creativity and Innovation Management, 14: 2, 142-150.

Robert, C. ve Wasti, S. A. (2002). Organizational Individualism and Collectivism: Theoretical Development and an Empirical Test of a Measure. Journal of Management, 28: 4, 544-566.

Sanders, K., Dorenbosch, L. ve De Reuver, R. (2008). The Impact of Individual and Shared Employee Perceptions of HRM on Affective Commitment: Considering Climate Strength. Personnel Review, 37: $4,412-425$.

Schepers, P. ve Van Den Berg, P. T. (2007). Social Factors of Work Environment Creativity. Journal of Business and Psychology, 21: 3, 407-428.
Schneider, S. C. (1988). National vs. Corporate Culture: Implications for Human Resource Management. Human Resource Management, 27: 2, 231-246.

Schuler, R. S. ve Jackson, S. E. (1987). Linking Competitive Strategies with Human Resource Management Practices. The Academy of Management Executive, 1: 3, 207-219.

Schwartz, H. ve Davis, S. M. (1981). Matching Corporate Culture and Business Strategy. Organizational Dynamics, 10, 30-48.

Scott, S. G. ve Bruce, R. A. (1994). Determinants of Innovative Behavior: A Path Model of Individual Innovation in the Workplace. The Academy of Management Journal, 37: 3, 580-607.

Shalley, C. E. ve Gilson, L. L. (2004). What Leaders Need to Know: A Review of Social and Contextual Factors that can Foster or Hinder Creativity. The Leadership Quarterly, 15, 33-53.

Shipton, H., Fay, D., West, M., Patterson, M. ve Birdi, K. (2005). Managing People to Promote Innovation. Creativity and Innovation Management, 14: 2, 118128.

Tichy, N. M. (1982). Managing Change Strategically: The Technical Political and Cultural Keys. Organizational Dynamics, 11, 59-80.

Tsui, A. S., Pearce, J. L., Porter, L. W. ve Hite, J. P. (1995). Choice of EmployeeOrganization Relationship: Influence of External and Internal Organizational Factors. G.R. Ferris (Ed.), Research in Personnel and Human Resource Management, 13, Greenwich, CT: JAI Press, s. 117-151.

Tsui, A.S, Pearce, J. L., Porter, L. W. ve Tripoli, A. M. (1997). Alternative Approaches to the Employee-Organization Relationship: Does Investment in Employees Pay Off? Academy of Management Journal, 40: 5, 1089-1121.

Uen, J. F., Chien, M. S. ve Yen, Y. F. (2009). The Mediating Effects of Psychological Contracts on the Relationship Between Human Resource Systems and Role 
Behaviors: A Multilevel Analysis. Journal of Business Psychology, 24, 215223.

Wallach, E. J. (1983). Individuals and Organizations: The Cultural Match. Training and Development Journal, 2936.

Wei, L. Q., Liu, J. ve Herndon, N. C. (2011). SHRM and Product Innovation: Testing the Moderating Effects of Organizational Culture and Structure in Chinese Firms. The International Journal of Human Resource Management, 22: 1, 19-33.

Wei, L. Q., Liu, J., Zhang, Y. ve Chiu, R. K. (2008). The Role of Corporate Culture in the Process of Strategic Human Resource Management: Evidence from Chinese Enterprises. Human Resource Management, 47: 4, 777-794.

West, M. A., Hirst, G., Richter, A. ve Shipton, H. (2004). Twelve Steps to Heaven: Successfully Managing Change through Developing Innovative Teams. European Journal of Work and Organizational Psychology, 13: 2, 269 - 299.

Wilkins, A. L. (1984). The Creation of Company Cultures: The Role of Stories and Human Resource Systems. Human Resource Management, 23: 1, 41-60.

Woodman, R. W., Sawyer, J. E. ve Griffin, R. W. (1993). Toward a Theory of Organizational Creativity. Academy of Management Review, 18: 2, 293-321.

Wright, P. M., McMahan G. C. ve McWilliams, A. (1994). Human Resources and Sustained Competitive Advantage: A Resource-Based Perspective. International Journal of Human Resource Management, 5:2 301-326. 